\title{
The dark side of light. Light pollution kills leatherback turtle hatchlings
}

\author{
Marina Zheleva
}

Dundee Science Press, Dundee, Scotland

\begin{abstract}
The leatherback turtle is the largest and most migratory of all sea turtles and deepest diving air-breathing animal. It has unique physiology which allows it to adapt to various habitats ranging from sub-polar to equatorial during its migrations. The leatherback turtle is also the only sea turtle where no cases of tumours have been diagnosed. These unique features add to the arguments for preservation of this endangered species. Here we discuss the effect of light pollution on leatherback turtle hatchlings in Tobago and the measures for their protection.
\end{abstract}

Citation: Zheleva M. The dark side of light. Light pollution kills leatherback turtle hatchlings. Biodiscovery 2012; 3: 4. DOI: 10.7750/BioDiscovery.2012.3.4

Copyright: (C) 2012 Zheleva. This is an open-access article distributed under the terms of the Creative Commons Attribution License, which permits unrestricted use, provided the original authors and source are credited.

Received: 25 September 2012; Accepted: 26 September 2012; Available online /Published: 30 September 2012

Corresponding Author: Marina Zheleva, e-mail: marina.zheleva@biodiscovery journal.co.uk

The leatherback turtle (Dermochelys coriacea), is the largest of all living turtles and can reach more than 3 meters from head to tail and weighs more than $900 \mathrm{~kg}$. They are unique amongst reptiles for their ability to maintain high body temperatures using metabolically generated heat. It has been measured experimentally that leatherback turtles can maintain deep body temperature of 18 degrees $\mathrm{C}$ above water temperature [1]. The leatherback turtle is an air-breathing diving animal capable of maintaining activity during prolonged dives fuelled by its oxygen stores. The longest reported dive lasted 86.5 minutes [2], and dives as deep as 1,230 metres [3] and 1280 meters [4] were recorded.

Leatherback turtles have unique anatomy and physiology. They have the most hydrodynamic body design of any sea turtle. Instead of bony carapace the leatherback turtles have thick, leathery skin with embedded minuscule osteoderms. They are the only reptiles which lack $\beta$-keratin in their scales. Leatherback turtles differ from other sea turtles in their susceptibility to diseases. For example a disease known as fibropapillomatosis which manifests through external tumours in sea turtles have never been diagnosed in leatherback turtles. Unique physiology of leatherback turtles has important implications for understanding vertebrate biology, and is another strong argument for preservation of this endangered species.

Although leatherback turtles have survived on this planet for over 150 million years, the impacts of recent human activities have resulted in a dramatic decline in their population. In many countries they are captured, killed, and traded for their meat, shells and their leather flippers. In addition many turtles die due to injuries or drowning caused by being accidentally caught by fishing boats. Other factors threatening leatherbacks globally include loss or degradation of nesting habitat from coastal development, nest predation by native and nonnative predators, marine pollution and debris.

Here we describe our observations on the threat of artificial lighting to survival of hatchlings in the Turtle beach in Tobago. Trinidad and Tobago are amongst the most important leatherback nesting sites in the world, with approximately $20 \%$ of the total world population nesting in these islands. One of the primary leatherback nesting beaches in Tobago is the Turtle Beach, which is part of the Great Courland Bay on the island's north west coast. Hundreds of nests are laid annually on the beach with around 110 eggs per clutch, $85 \%$ of which are viable. The unviable eggs are smaller, filled mostly with water and laid on top of the viable eggs. The 
presence of villas and hotels near the beach results in constant light pollution of the nests. The eggs hatch in about sixty to seventy days. Hatchlings usually emerge from the nest at night due to the favourable cooler temperatures. The unviable eggs burst during the hatchlings' scramble to the surface and the water that is released from them provide an easier path for the hatchlings. Once on the surface they use moon light and its reflections from water to find their way to the sea at night.

In August 2012 we witnessed the effect of artificial lights on the leatherback hatchlings' orientation on the Turtle Beach. Observation on morning track on the beach (Figure 1) demonstrates that a large number of hatchlings are disoriented and heading inland instead of out to sea.

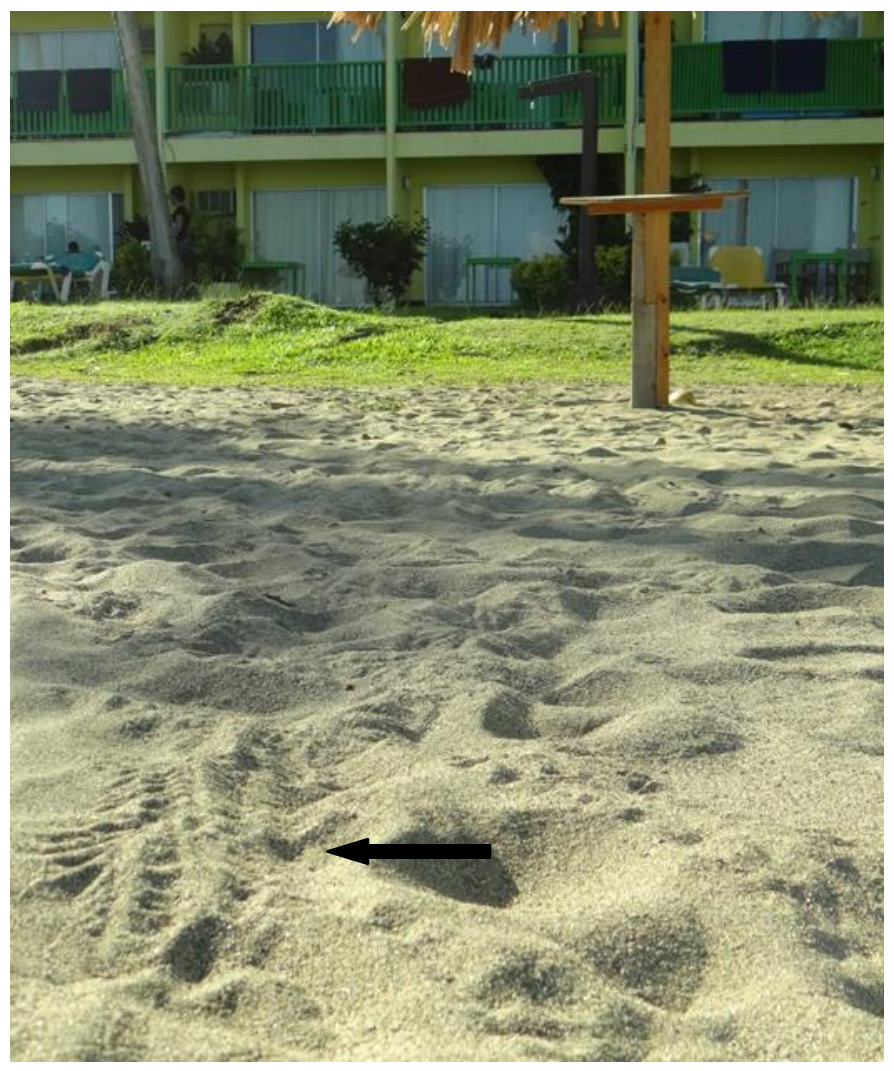

Figure 1. Leatherback hatchlings' tracks (indicated by an arrow) on the Turtle beach demonstrate that hatchlings are heading towards the artificial lights instead to the sea.

We have found hatchlings which had died of dehydration in the sun (Figure 2) and witnessed incidents when they were caught by predators like birds or dogs during daylight. These incidents demonstrate that currently artificial lighting of the nesting beaches is the biggest threat to survival of hatchlings and a major factor in declining of leatherback turtle population.

At present the most effective measure to prevent turtle hatchlings disorientation are beach patrols. The work of Save Our Sea Turtles (SOS) - a registered

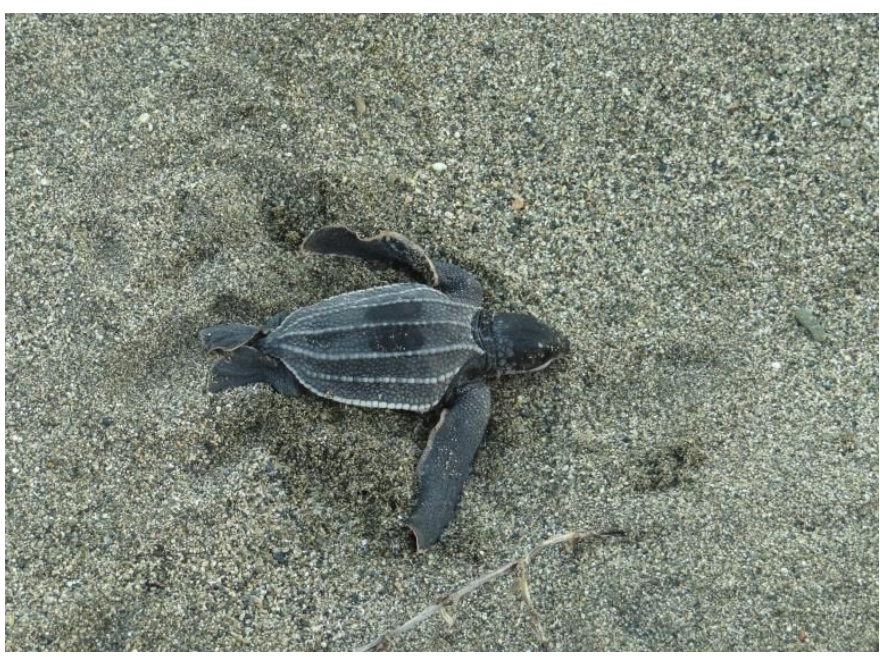

Figure 2. A disoriented hatchling has died of dehydration.

community based organization, founded in 2000 with a mission to conserve Tobago's sea turtles is already giving results. Regular patrols help disoriented hatchlings to find the sea and prevents poaching of these remarkable creatures (see Figure 3 and supplemental video).

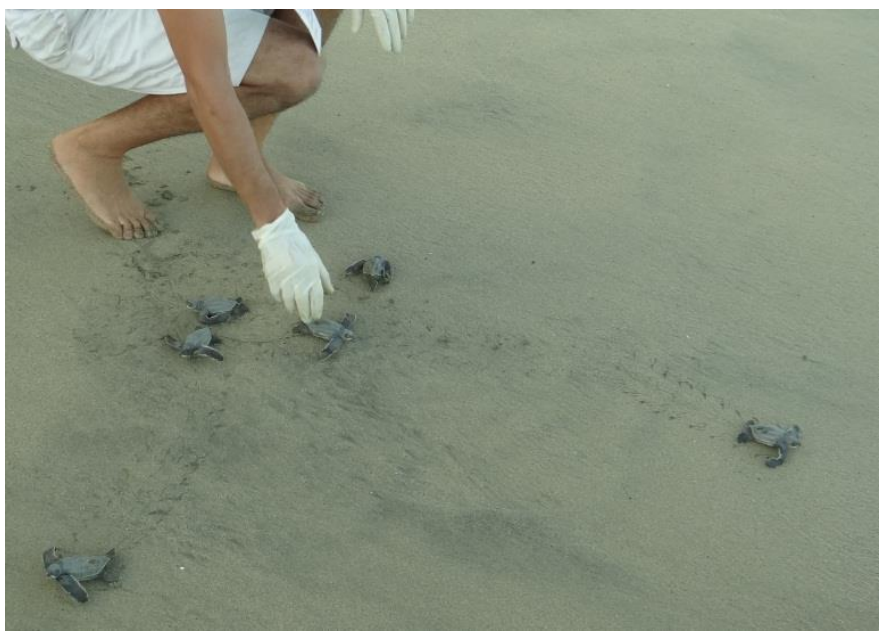

Figure 3. Releasing of leatherback turtle hatchlings in the sea by a Save Our Sea Turtles (Tobago) volunteer.

\section{References}

1. Frair W, Ackman RG, Mrosovsky N. Body Temperature of Dermochelys coriacea: Warm Turtle from Cold Water. Science 1972; 177(4051): 791-793.

2. López-Mendilaharsua M, Rochaa CFD, Domingoa A, Wallacea BP, Millera P. Prolonged deep dives by the leatherback turtle Dermochelys coriacea: pushing their aerobic dive limits. Marine Biodiversity Records 2009; 2: e35.

3. Hays GC, Houghton JDR, Myers AE. Endangered species: PanAtlantic leatherback turtle movements. Nature 2004; 429: 522.

4. Doyle TK, Houghton JDR, O'Súilleabháin PF, Hobson VJ, Marnell F, Davenport J, Hays GC. Leatherback Turtles Satellite Tagged in European Waters. Endang Species Res 2008; 4: 23-31. 